\title{
TRABALHO E EDUCAÇÃO: JUVENTUDE ENCARCERADA
}

\author{
Fernando Selmar Rocha FIDALGO ${ }^{1}$ \\ Universidade Federal de Minas Gerais \\ fernandos@fae.ufmg.br \\ Yara Elizabeth ALVES ${ }^{2}$ \\ Universidade Federal de Minas Gerais \\ yaraealves@gmail.com \\ Karol Oliveira de Amorim-SILVA ${ }^{3}$ \\ Universidade Federal de Minas Gerais \\ karol.amorim@ig.com.br
}

Resumo: Este artigo objetiva problematizar o encarceramento da juventude brasileira. A referida temática emerge das discussões realizadas no âmbito do Observatório Nacional do Sistema Prisional (ONASP) e do debate provocado pela Proposta de Ementa Constitucional (PEC) $n^{\circ} 171$ de 1993, que prevê a redução da maioridade penal de 18 para 16 anos, no caso de alguns crimes. Em termos metodológicos, foi realizado um levantamento dos documentos e dos dados sobre a população prisional brasileira, os jovens em cumprimento de medida socioeducativa e as taxas de ocupação da juventude do país. A discussão busca demonstrar que o histórico de exclusão social anterior ao encarceramento revela a iminente necessidade da inclusão dos jovens na esfera dos direitos. Entre esses, destaca-se o trabalho e a educação.

Palavras-chave: Juventude. Encarceramento. Trabalho. Educação.

\begin{abstract}
This article aims to discuss the imprisonment of Brazilian youth. This theme emerges from the discussions carried out within the framework of the Observatório Nacional do Sistema Prisional (ONASP) [National Observatory of Prison System] and the debate instigated by the Proposta de Emenda Constitucional (PEC) $n^{o} 171$ de 1993 [Proposal for Constitutional Amendment], which foresees the reducing the criminal liability from 18 to 16 years for some crimes. Concerning the methodology, it was carried out a survey of documents and data on the Brazilian prison population, young people in fulfillment of educational correctional measure and the country's youth occupation rates. The discussion seeks to demonstrate that the history of social exclusion previous to imprisonment reveals the imminent need of inclusion of young people in the sphere of rights, including the work and education.
\end{abstract}

Keywords: Youth. Imprisonment. Work. Education.

\footnotetext{
${ }^{1}$ Professor Titular da Faculdade de Educação (FaE) da Universidade Federal de Minas Gerais (UFMG). Doutor em Educação pela Pontifícia Universidade Católica de São Paulo (PUC-SP, 1999). Coordenador do Observatório Nacional do Sistema Prisional (ONASP).

${ }^{2}$ Graduada em Pedagogia pela Faculdade de Educação (FaE) da Universidade Federal de Minas Gerais (UFMG). Mestranda em Educação no Programa de Pós-Graduação: Conhecimento e Inclusão Social (FaE/UFMG). Pesquisadora do Observatório Nacional do Sistema Prisional (ONASP).

${ }^{3}$ Mestra em Educação e Pedagoga, ambos pela Faculdade de Educação (FaE) da Universidade Federal de Minas Gerais (UFMG). Especialista em Criminalidade e Segurança Pública pela Faculdade de Filosofia e Ciências Humanas (FAFICH) da UFMG. Pesquisadora do Observatório Nacional do Sistema Prisional (ONASP).
} 


\section{Introdução}

Este artigo refere-se a um dos trabalhos desenvolvidos no âmbito do Observatório Nacional do Sistema Prisional (ONASP) e objetiva problematizar o encarceramento da juventude brasileira.

Essa temática emerge das discussões realizadas no contexto do ONASP, mas também do debate provocado pela tramitação no Congresso Nacional da Proposta de Ementa Constitucional (PEC) $n^{\circ} 171$ de $1993^{4}$, que pretende alterar a redação do art. 228 da Constituição Federal, com o intuito de reduzir a maioridade penal de 18 para 16 anos, nos casos de crimes hediondos, crimes de homicídio doloso e lesão corporal seguida de morte.

Frente ao mencionado, parece relevante discutir o perfil da população prisional do país, formada majoritariamente por jovens, negros, de baixa escolaridade e baixa renda (conforme será demonstrado através dos dados analisados).

A explicitação desse perfil não pretende, de forma alguma, demonstrar que o problema criminal do país se resume ao trinômio preto-pobre-vagabundo. Aliás, tal discurso, que tem sido imensamente repercutido pela mídia e pela sociedade, além de endossar o processo de seletividade penal, aponta como "solução" para a questão criminal uma "única" via capaz de coibir esse “criminoso em potencial": o agravamento da punição (ALVES, 2013, p.19).

O que se pretende, neste trabalho, é, em oposição a esse discurso acrítico, discutir o crime e a criminalização enquanto produções histórico-sociais. Sendo assim, é imprescindível considerar, por exemplo, as relações entre o modo de produção social e o sistema penal.

As formas de controle social na sociedade capitalista estão sob o jugo do poder econômico, que utiliza o sistema punitivo para defender a divisão de classes, a propriedade privada, a exploração do trabalho, enfim, tudo o que é necessário para a manutenção das relações sociais desigualmente estabelecidas (Ibidem, p. 21).

Nesse sentido, o domínio econômico exerce influência nas políticas penais do país, que têm sido direcionadas às populações jovens de determinados grupos sociais e étnicos. Associado a isso, há, por parte da sociedade, a crença na punição (tanto preventiva quanto retributiva), uma ética da

\footnotetext{
${ }^{4}$ A Câmara dos Deputados aprovou no dia 19 de agosto, em segundo turno, por 320 votos a favor, 152 contra e 1 abstenção, a PEC que reduz a maioridade penal de 18 para 16 anos no caso de crimes de homicídio doloso, lesão corporal seguida de morte e crimes hediondos. O texto segue para o Senado, em que precisará passar por duas votações para ser promulgado.
} 
vingança que desconsidera os efeitos nefastos do encarceramento na vida das pessoas e da comunidade como um todo.

A cada novo fato que gera comoção social, a privação da liberdade ou o agravamento da punição são apontados como a "fórmula ideal" para a resolução das questões. Assim, o cerne da questão passa a ser as políticas penais em detrimento das políticas sociais. Como afirma Wacquant (2001), cada vez mais se verifica, em todo o mundo, a adoção de uma política de administração da pobreza pela via penal, que, em alguns casos, complementa, e, em outros, substitui as políticas assistenciais.

O que se busca neste artigo é demonstrar que o histórico de exclusão social anterior ao aprisionamento revela a iminente necessidade da inclusão dos jovens na esfera dos direitos. Entre esses direitos, destaca-se o trabalho e a educação, que devem ser garantidos tanto aos jovens e adultos em liberdade, quanto aos que estão sob a custódia do Estado.

\section{Procedimentos metodológicos}

Tendo em vista a problemática apresentada, foi realizado um levantamento dos dados e documentos que versam sobre o tema. O intuito era identificar, sistematizar e analisar as informações acerca da população prisional brasileira, dos jovens em cumprimento de medida socioeducativa e das taxas de ocupação da juventude do país. Esclarece-se que, neste trabalho, são consideradas jovens as pessoas com idade entre 15 e 29 anos de idade, conforme prevê o Estatuto da Juventude (BRASIL, 2013).

Empreendeu-se uma análise do Levantamento Nacional de Informações Penitenciárias publicado em 2015, que apresenta dados referentes a junho de 2014 (últimos disponíveis). Esse documento resulta de alterações, realizadas em 2014, na metodologia e no instrumento de coleta de informações do Sistema Integrado de Informações Penitenciárias (Infopen).

Analisou-se o Mapa do Encarceramento: os jovens do Brasil (2015), elaborado com base nos dados disponibilizados pelo Infopen e nas informações referentes aos jovens em medidas socioeducativas, do Sistema Nacional de Atendimento Socioeducativo (SINASE). Ressalta-se que, embora o Mapa do Encarceramento apresente os dados do Infopen, os mesmos são referentes ao ano de 2012, portanto estão desatualizados. Nesse sentido, optou-se por trabalhar com os dados do 
Infopen que constam na publicação mencionada anteriormente, Levantamento Nacional de Informações Penitenciárias (junho de 2014).

Foi consultado também o $9^{\circ}$ Anuário Brasileiro de Segurança Pública (2015) e os dados do Instituto Brasileiro de Geografia Estatística (IBGE), que constam no documento Síntese de Indicadores Sociais (2013) e no Censo Demográfico (2010).

Além das fragilidades específicas de cada um dos documentos analisados, que acabam por impossibilitar um maior detalhamento analítico, outro desafio deste trabalho foi tratar de dados que se referem a períodos distintos. Assim, por exemplo, os dados da população prisional se referem a junho de 2014 e do sistema socioeducativo ao ano de 2012.

Não obstante, considerou-se que realizar a análise proposta seria de suma importância, até mesmo para explicitar a importância de um sistema de dados integrado e confiável.

\section{População prisional brasileira}

Segundo dados do Infopen, em junho de 2014, o país tinha 607.731 mil pessoas privadas de liberdade. Abaixo, a Tabela 1 apresenta um panorama geral da população prisional brasileira.

Tabela 1- População prisional brasileira em junho de 2014

\begin{tabular}{c|c}
\hline População prisional & $\mathbf{6 0 7 . 7 3 1}$ \\
\hline Sistema Penitenciário & 579.423 \\
Secretarias de Segurança/Carceragens de delegacias & 27.950 \\
Sistema Penitenciário Federal & 358 \\
\hline Vagas & $\mathbf{3 7 6 . 6 6 9}$ \\
\hline Déficit de vagas & $\mathbf{2 3 1 . 0 6 2}$ \\
\hline Taxa de ocupação & $\mathbf{1 6 1 \%}$ \\
\hline Taxa de aprisionamento & $\mathbf{2 9 9 , 7}$ \\
\hline
\end{tabular}

Fonte: Infopen, jun. 2014; Senasp, dez. 2013; IBGE, 2014.

É possível observar que o número de pessoas presas é consideravelmente superior às 376.609 mil vagas do sistema prisional, totalizando um déficit de 231.062 vagas. A taxa de ocupação média dos estabelecimentos é de $161 \%$, ou seja, em um espaço concebido para custodiar 
10 pessoas, existem por volta de 16 indivíduos encarcerados. Já a taxa de aprisionamento ${ }^{5}$ é de 299,7. Em outros termos, existem cerca de 300 presos para cada cem mil habitantes no país (BRASIL, 2015a, p.11).

Por si só, esse quadro demonstra a gravidade da situação do sistema prisional brasileiro. Ao compará-lo com a realidade de outros países, é possível observar que, em números absolutos, o Brasil tem a quarta maior população prisional do mundo, os três primeiros são, respectivamente, Estados Unidos (2.228.424), China (1.657.812) e Rússia (673.818).

Quando considerada a taxa de aprisionamento dos países, verifica-se que o Brasil também fica em quarto lugar (299,7): somente os Estados Unidos (698), a Rússia (468) e a Tailândia (457) têm um contingente prisional mais elevado (Ibidem, p.13).

O mais preocupante é que a taxa de aprisionamento brasileira apresenta uma tendência contrária aos demais países (Estados Unidos, China e Rússia), que estão reduzindo seu ritmo de encarceramento, enquanto que o Brasil vem aumentando esse ritmo, conforme pode ser visualizado na Figura 1.

Figura 1- Variação da taxa de aprisionamento entre 2008 e 2014 nos quatro países com maior população prisional do mundo

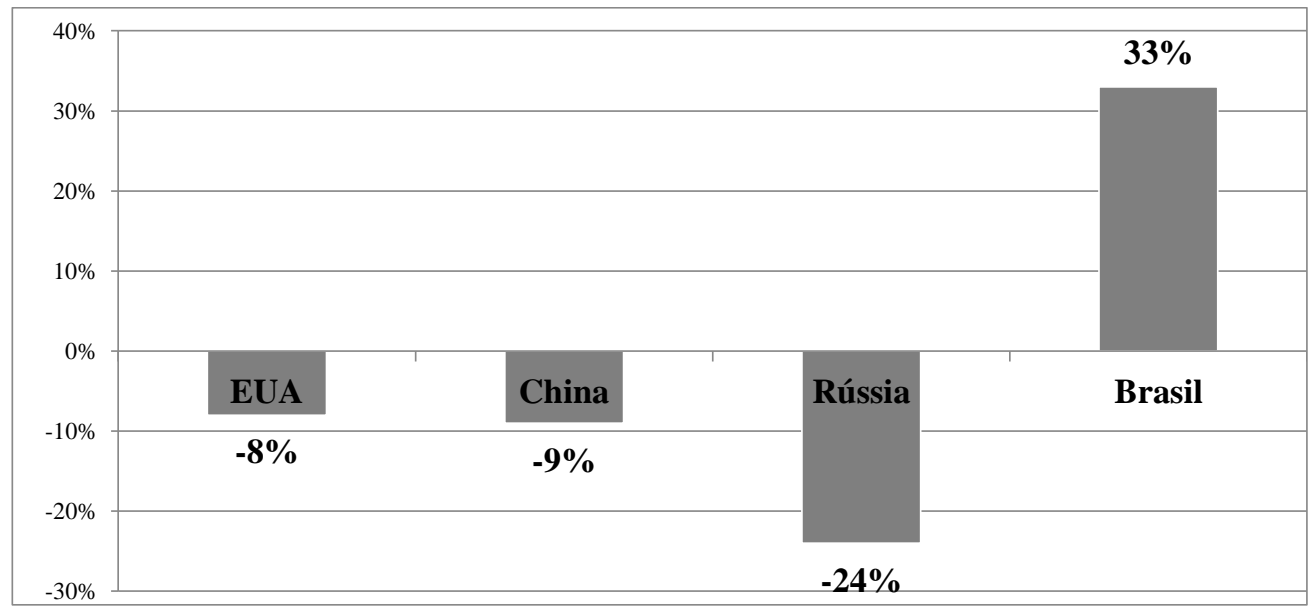

Fonte: Infopen, jun.2014.

\footnotetext{
${ }^{5} \mathrm{~A}$ taxa de aprisionamento indica o número de pessoas presas para cada cem mil habitantes. O objetivo de utilizar essa medida é permitir a comparação entre locais com diferentes tamanhos de população e neutralizar o impacto do crescimento populacional, permitindo a comparação a médio e longo prazo (BRASIL, 2015, p.13).
} 
Se mantida essa tendência de aceleração do encarceramento, pode se projetar que a população privada de liberdade do Brasil ultrapassará a da Rússia em 2018 (Ibidem, p.15).

A Figura 2 demonstra a evolução do número de pessoas presas no Brasil de 1990 a 2014.

Figura 2- Evolução do número de pessoas privadas de liberdade no Brasil

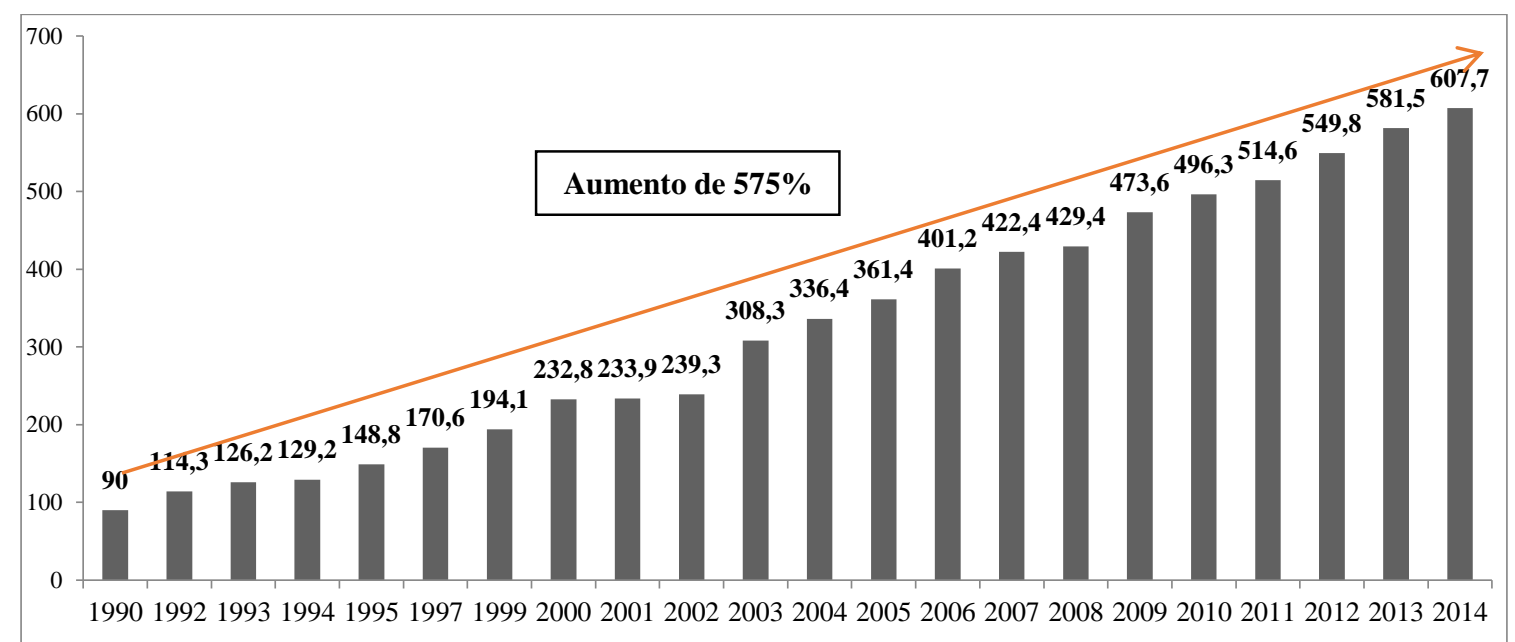

Fonte: Ministério da Justiça - a partir de 2005, dados do Infopen/MJ.

Observa-se que o número de pessoas presas em 2014 é 6,7 maior do que em 1990. Desde o ano 2000, "a população prisional cresceu em média 7\% ao ano, resultando em um crescimento de $161 \%$, valor dez vezes maior que o crescimento do total da população brasileira, que apresentou aumento de $16 \%$ no período e em média 1,1\% ao ano" (BRASIL, 2015a, p.15).

Caso o crescimento da população carcerária continue nesse ritmo, em 2022 o número de pessoas presas no país ultrapassará a marca de um milhão de indivíduos. Em 2075, uma em cada dez pessoas estará em situação de privação de liberdade (Ibidem, p.16). As projeções são alarmantes e promovem diversos questionamentos, tais como: quais interesses estão por trás da adoção de políticas que tendem a aumentar o número de pessoas presas do país? Quem se beneficia quando o país tem uma das maiores populações prisionais do mundo? Como romper com o ciclo de hiperencarceramento?

No que diz respeito ao perfil da população prisional, foram analisados os dados referentes à faixa etária, raça, cor ou etnia e grau de escolaridade das pessoas privadas de liberdade. 
Quanto à faixa etária das pessoas presas, o Infopen obteve informações de cerca de $70 \%$ do total de pessoas presas do país. A Tabela 2 apresenta a distribuição da população carcerária por faixa etária. Observa-se que a maior parte da população prisional é formada por jovens, correspondendo a $56 \%$ do total (quando somado o percentual de $25 \%$ referente à faixa etária de 25 a 29 anos e de $31 \%$ da faixa de 18 a 24 anos).

Tabela 2- Faixa etária das pessoas privadas de liberdade

\begin{tabular}{c|c}
\hline $\mathbf{1 8}$ a 24 anos & $\mathbf{3 1 \%}$ \\
\hline 25 a 29 anos & $\mathbf{2 5 \%}$ \\
\hline 30 a 34 anos & $19 \%$ \\
\hline 35 a 45 anos & $17 \%$ \\
\hline 46 a 60 anos & $7 \%$ \\
\hline 61 a 70 anos & $1 \%$ \\
\hline 71 anos ou mais & $0 \%$ \\
\hline
\end{tabular}

Fonte: Infopen, jun. 2014

Ao comparar o perfil da população prisional com o perfil da população brasileira em geral, observa-se que a proporção de jovens é maior na população prisional. Uma vez que " $56 \%$ da população prisional é composta por jovens, essa faixa etária compõe apenas 21,5\% da população total do país (segundo dados do IBGE, do Censo de 2010)” (BRASIL, 2015a, p. 48).

Em relação à raça, cor ou etnia o Infopen apresenta dados de $45 \%$ da população prisional brasileira. A Tabela 3 demonstra esses dados.

Tabela 3- Raça, cor ou etnia da população prisional brasileira

\begin{tabular}{c|c}
\hline Negra & $\mathbf{6 7 \%}$ \\
\hline Branca & $31 \%$ \\
\hline Amarela & $1 \%$ \\
\hline Indígena & $0 \%$ \\
\hline Outras & $1 \%$ \\
\hline
\end{tabular}

Fonte: Infopen, jun. 2014 e IBGE, 2010.

MARGENS - Revista Interdisciplinar

Versão Digital - ISSN: 1982-5374
Dossiê: Trabalho e Educação Básica VOL.11. N. 16. Jun 2017. (p. 131-147) 
Observa-se que 67\% das pessoas privadas de liberdade são negras. Há, portanto, a seguinte proporção: dois em cada três presos são negros. Ao passo que a porcentagem de pessoas negras no sistema prisional é de $67 \%$, na população brasileira em geral, a proporção é significativamente menor $(51 \%)$. Essa tendência é observada tanto na população prisional masculina quanto na feminina (BRASIL, 2015a, p.50).

Em relação ao grau de escolaridade das pessoas privadas de liberdade, o Infopen apresenta as informações de cerca de $40 \%$ do total da população, ilustradas na Figura 3. Como é possível observar na Figura 3, o grau de escolaridade da população prisional brasileira é extremamente baixo: $6 \%$ dos presos são analfabetos, $9 \%$ alfabetizados sem cursos regulares, $53 \%$ têm o ensino fundamental incompleto e $12 \%$ o ensino fundamental completo. Aproximadamente oito em cada dez pessoas presas estudaram, no máximo, até o ensino fundamental, enquanto a média nacional de pessoas que não frequentaram o ensino fundamental, ou o têm incompleto, é de 50\% (BRASIL, 2015a, p.58).

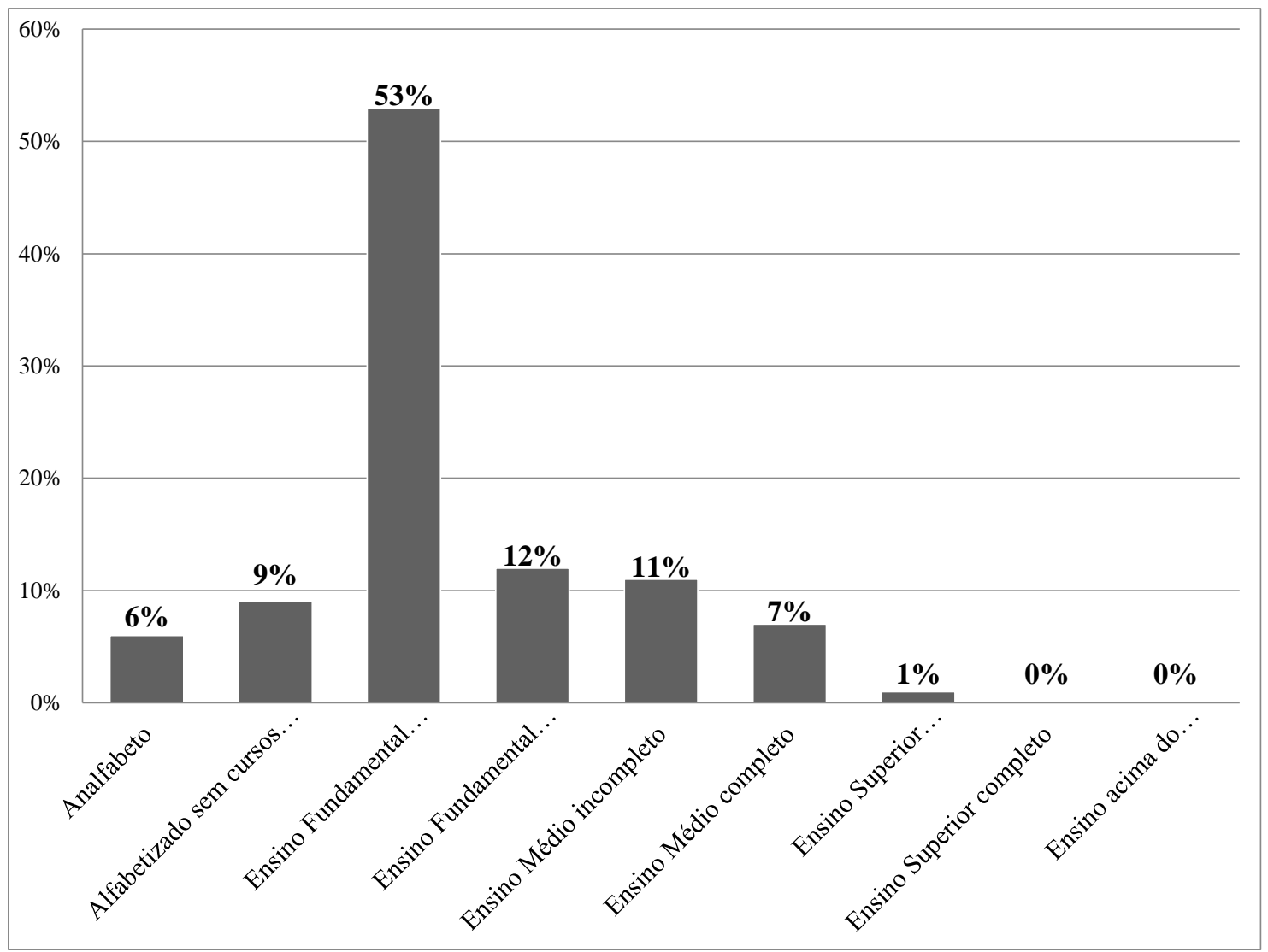

Figura 3 - Escolaridade da população prisional brasileira Fonte: Infopen, jun. 2014.

MARGENS - Revista Interdisciplinar

Versão Digital - ISSN: 1982-5374
Dossiê: Trabalho e Educação Básica VOL.11. N. 16. Jun 2017. (p. 131-147) 
Na população brasileira em geral, $32 \%$ das pessoas completaram o ensino médio (IBGE, 2010), enquanto apenas $7 \%$ da população prisional o concluíram, entre as mulheres presas, essa proporção é de 14\% (BRASIL, 2015a, p.58).

É importante destacar que o percentual de pessoas envolvidas em atividades educacionais nas unidades prisionais é de 10,7\%, número pequeno, principalmente, ao se levar em conta o baixo nível de escolaridade da população prisional, conforme já demonstrado. Do total de pessoas que estão exercendo atividades educacionais nos estabelecimentos prisionais, $61 \%$ cursa o ensino fundamental, haja vista que $53 \%$ dessa população não possui o ensino fundamental completo.

No que tange ao fator trabalho, segundo dados da Previdência Social, em 2013, o número de presos que recebiam o Auxílio-Reclusão ${ }^{6}$ no Brasil era de 25.211. Considerando que, no referido ano (2013), o número de presos era 574.027, o percentual dos que recebiam tal auxílio era de 4,3\%. Ou seja, um pequeno número de reclusos, anteriormente à prisão, possuía vínculo trabalhista de carteira assinada com contribuição por mais de dois anos.

Esse dado nos possibilita pensar que se trata de uma classe trabalhadora na informalidade que não teve acesso à inclusão produtiva no mercado de trabalho formal. Além disso, é preciso considerar a possibilidade de poucos presos receberem esse auxílio por conta da reincidência. Outra possibilidade é a de que, como a população prisional é formada majoritariamente por jovens, muitas vezes esses não chegaram a entrar no mercado de trabalho formal, fato que é agravado pela falta de qualificação profissional.

Segundo dados do Infopen (2014), a porcentagem da população reclusa inserida em atividades laborativas era de 16\%. Da mesma forma que o número de presos envolvidos nas atividades educacionais, o de pessoas inseridas em atividade laboral nas prisões é pequeno.

Quanto à natureza da prisão e o tipo de regime, conforme informações do Infopen (2014), $41 \%$ dos presos brasileiros são provisórios (sem condenação). Entre os condenados $41 \%$ das

\footnotetext{
${ }^{6} \mathrm{O}$ Auxílio-reclusão é um benefício debitado aos dependentes do cidadão recluso no sistema penitenciário em regime fechado ou semiaberto que tenha contribuído para o Regime Geral da Previdência Social (RGPS), desde que ele não receba salário de empresa nem benefício do INSS. Para que os dependentes tenham direito a esse benefício, é necessário que o último salário recebido pelo cidadão que foi preso, tomado em seu valor mensal, esteja dentro do limite previsto pela legislação (atualmente igual ou menor que $\mathrm{R} \$ 1.089,72$ ). Caso o último salário do cidadão esteja acima deste valor, não há direito ao benefício. Há ainda a exigência de carência de pelo menos 24 contribuições mensais. Fonte: Site Previdência Social. Disponível em: < http://www.previdencia.gov.br/servicos-ao-cidadao/todosos-servicos/auxilio-reclusao/>. Acesso em: 12/09/15.
} 
pessoas privadas de liberdade cumprem pena em regime fechado. Apenas $3 \%$ dos presos estão em regime aberto e $15 \%$ em semiaberto. Para cada pessoa no regime aberto, há 14 pessoas no regime fechado; para cada pessoa do regime semiaberto, há aproximadamente 3 no fechado (BRASIL, 2015, p.20).

Também se verificou que $29 \%$ dos presos cumprem pena de mais de quatro a oito anos de reclusão; e $21 \%$ cumpre pena de até quatro anos, que, de acordo com a legislação, poderiam ser substituídas por penas alternativas em grande parte dos casos.

Com relação ao tipo de crimes tentados/consumados entre os registros das pessoas privadas de liberdade, o Infopen apresenta as seguintes informações:

[...] quatro entre cada dez registros correspondem a crimes contra o patrimônio. Cerca de um em cada dez corresponde a furto. Percebe-se que o tráfico de entorpecentes é o crime de maior incidência, respondendo por $27 \%$ dos crimes informados. Em seguida o roubo, com $21 \%$. Já o homicídio corresponde a $14 \%$ dos registros e o latrocínio a apenas 3\% (BRASIL, 2015a, p.69).

Ressalta-se, portanto, que a maioria dos privados de liberdade estão reclusos por crimes que não se configuram como "contra a vida".

Em síntese, os dados analisados demonstram que o encarceramento brasileiro incide sobre homens, negros, jovens, autores de crimes patrimoniais e que, em sua maioria, não chegaram a completar o ensino fundamental (BRASIL, 2015a, p.38).

\section{Jovens em cumprimento de medidas socioeducativas}

Segundo o Anuário Brasileiro de Segurança Pública, em 2013 havia 23.066 jovens em cumprimento de medida socioeducativa no país. A evolução desse número é expressa na Figura 4. 
Figura 4- Evolução de jovens em cumprimento de medida socioeducativa - Brasil: 1996-2013

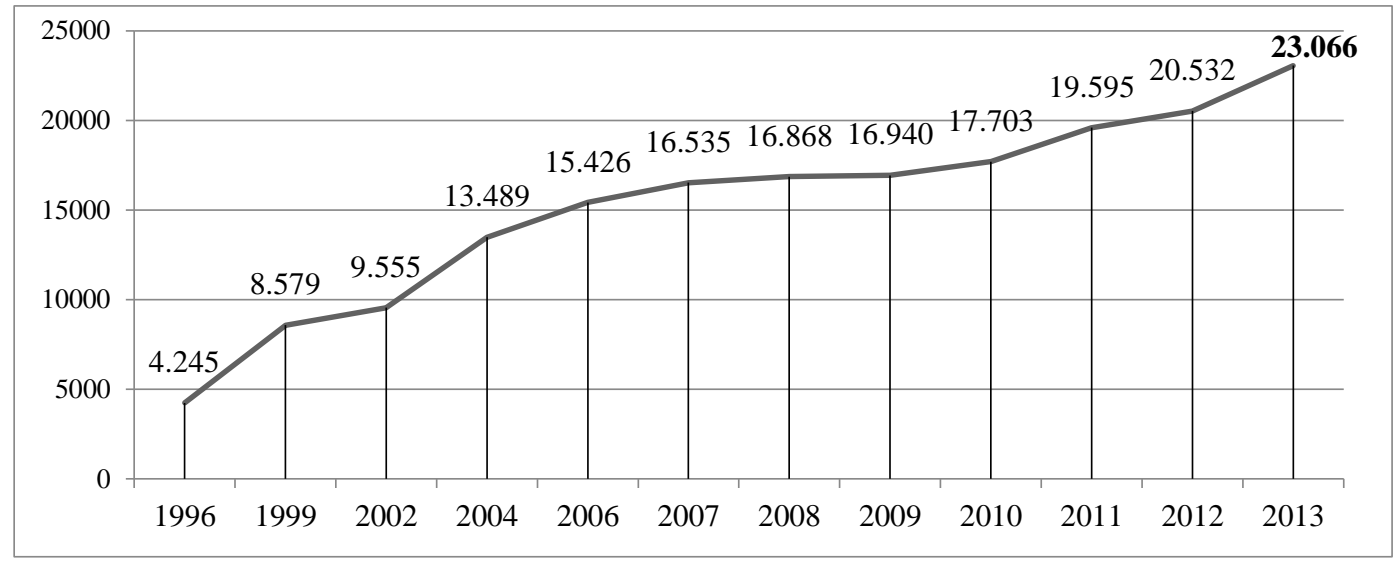

Fonte: $9^{\circ}$ Anuário Brasileiro de Segurança Pública, 2015.

Quanto aos atos infracionais cometidos, nacionalmente, em 2013, o roubo representou $42 \%$ (10.051) dos atos infracionais cometidos por jovens no país, seguido pelo tráfico de drogas com 24,8\%, (5.933) dos casos, e pelo homicídio 9,2\% (2.260), já o furto representou 3,6\% (856) e a tentativa de homicídio 3,10\% (747). Os demais atos infracionais (porte de arma de fogo, latrocínio, tentativa de roubo e estupro) variaram entre $2 \%$ e $1 \%$, conforme a Figura 5. Para efeito analítico, foi criada a categoria 'agrupados' com os atos que não tiveram representatividade maior que $1 \%$, conforme detalhamento na Figura 5.

Figura 5- Percentual dos atos infracionais

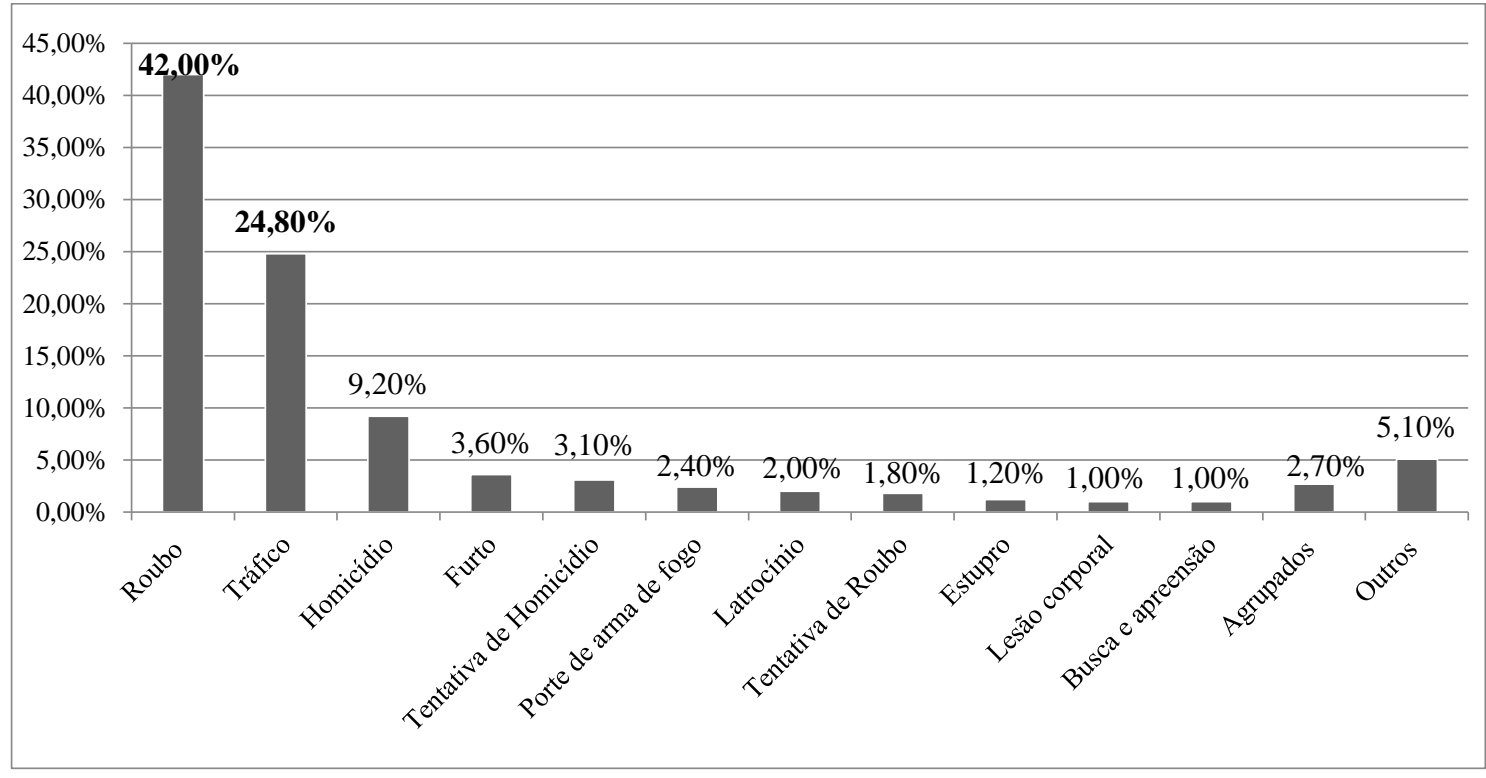

Fonte: 9 Anuário Brasileiro de Segurança Pública, 2015.

MARGENS - Revista Interdisciplinar

Versão Digital - ISSN: 1982-5374
Dossiê: Trabalho e Educação Básica VOL.11. N. 16. Jun 2017. (p. 131-147) 
O Mapa do Encarceramento aponta que, em 2012, existiam 100 adolescentes em cumprimento de medida restritiva de liberdade por 100 mil habitantes adolescentes (BRASIL, 2015, p.73). A maioria desses adolescentes cumpria medida de internação, demonstrando uma clara preferência pela reclusão do jovem em detrimento das demais medidas e sanções socioeducativas que possibilitam seu cumprimento em liberdade.

Os dados disponibilizados sobre o sistema socioeducativo brasileiro não permitem um maior detalhamento analítico. Não é possível traçar um perfil detalhado da juventude que está cumprindo pena: nível de escolaridade, aspectos familiares, quantidade de anos a que foi submetido à medida socioeducativa, reincidência, entre outros. Assim, os estudos ficam restritos aos aspectos mais gerais, como número de adolescentes internados e tipos de atos infracionais praticados (BRASIL, 2015b, p.93).

Essa incompletude dos dados, obviamente, evidencia a necessidade de os setores governamentais investirem mais esforços na coleta e sistematização de informações que permitam à sociedade visualizar o perfil dos jovens que cumprem medidas socioeducativas. Além disso, esse conhecimento é fundamental para a elaboração de políticas públicas condizentes.

A análise comparativa entre os dados do Mapa da Violência e do Mapa do Encarceramento demonstra que homens, jovens e negros são a maioria das vítimas de homicídio e da população prisional brasileira. Esses dados apontam que "as instituições da segurança pública e da justiça criminal do país identificam este grupo da população como alvo de intenso controle, flagrando em maior intensidade as suas condutas ilegais, com práticas que produzem violência e morte" (BRASIL, 2015b, p. 87-88).

Diante do exposto, evidencia-se a seletividade racial do encarceramento brasileiro, já que a aceleração do encarceramento é maior entre os negros do que entre brancos, bem como a vulnerabilidade da população negra e jovem às mortes violentas (BRASIL, 2015b).

Os números expressam também a tendência de hiperencarceramento na atualidade brasileira, denominada por Wacquant $(2003,2009)$ como a extensão do Estado Penal ${ }^{7}$ que, por

\footnotetext{
${ }^{7}$ Termo utilizado por Wacquant (2003) para designar o Estado que criminaliza a miséria. O Estado Penal opõe-se ao Estado Social, no qual 'a criminalização da marginalidade e a 'contenção punitiva' das categorias deserdadas faz as vezes da política social” (p. 20). Ao mesmo tempo em que "[...] os benefícios que distribui são cada vez mais monopolizados pelos privilegiados; sua vocação disciplinar se afirma principalmente na direção das classes étnicas dominadas" (p. 21).
} 
meio da expansão e intensificação das atividades policiais e de justiça criminal, focaliza sua atuação punitiva em determinados grupos sociais. Sua política é direcionada, primeiramente, à questão de classes; em segundo, às questões raciais; e, por último, ao espaço físico.

Esse fenômeno reafirma a seletividade penal, que, além de maior rigidez com alguns segmentos sociais, incide seu punitivismo também, em determinados tipos de delitos (crimes patrimoniais e entorpecentes), característica do Estado Penal, que cresce de forma mais severa contra os crimes de menor poder ofensivo.

Confirma-se, portanto, que a aglutinação desses alvos configurou o perfil carcerário brasileiro descrito anteriormente, levando a esta problematização, especialmente quanto à forma como o modelo social e penal tem-se estabelecido no Brasil nos últimos 50 anos. O mesmo assumiu, assim como aponta Wacquant (2009 p. 12), uma definição do regime de marginalidade urbana, que emergiu nas sociedades avançadas desde o final da era Fordista, com destaque para quatro lógicas que se combinavam para produzi-lo: “a mudança macrosocietal resultante em desigualdades; a mutação do trabalho assalariado (o que implica tanto desproletarização como informalidade); a redução da segurança social e da concentração espacial; e a estigmatização da pobreza" (WACQUANT, 2009, p.12).

\section{Perspectivas da juventude: trabalho e educação}

As taxas de ocupação da juventude brasileira são demonstradas na Figura 6, em que é possível perceber que, dos jovens de 15 a 29 anos de idade, 21,6\% somente estuda, 13,6\% trabalha e estuda, 45,2\% somente trabalha e 19,6\% não trabalha nem estuda. Merecem destaque os jovens que não trabalhavam na semana de referência nem frequentavam escola, aqueles chamados de "nem-nem", que representavam 19,6\% dos jovens de 15 a 29 anos de idade, em 2012, ou seja, 9,6 milhões de pessoas, isto é, uma em cada cinco pessoas da respectiva faixa etária. 
Figura 6- Distribuição percentual dos jovens de 15 a 29 anos de idade, por tipo de atividade na semana de referência, segundo os grupos de idade, Brasil -2012

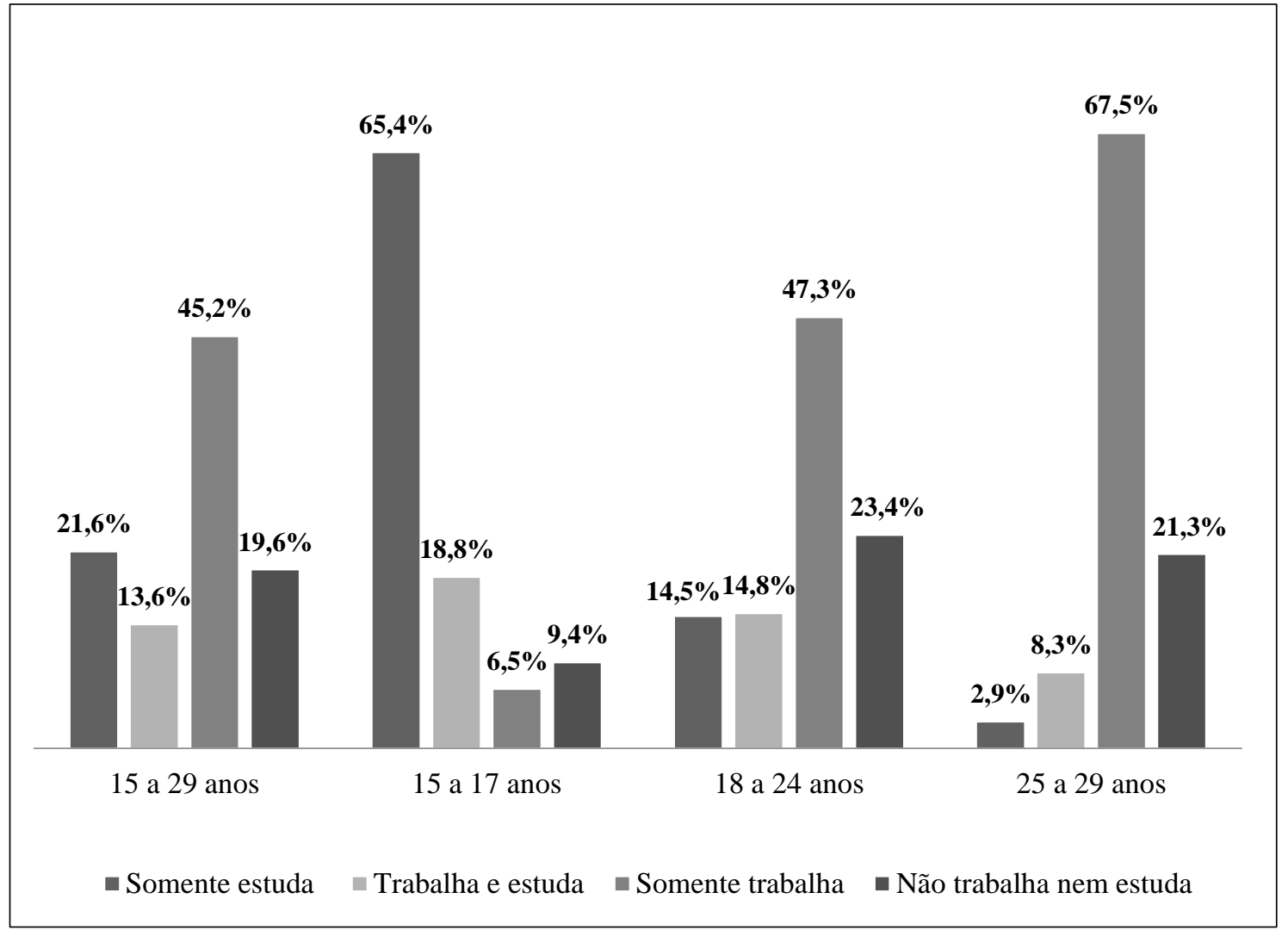

Fonte: IBGE, Pesquisa Nacional por Amostra de Domicílios, 2012.

Conforme dados do Observatório do Plano Nacional de Educação (PNE) no Brasil, cerca de 2,9 milhões de crianças e jovens de 4 a 17 anos estão fora da escola. Desses, aproximadamente 1,6 milhão são jovens de 15 a 17 anos, que deveriam estar cursando o Ensino Médio. Obviamente que as razões de um jovem não trabalhar e/ou não estudar são inúmeras e não se tem aqui a pretensão de explicá-las. O que se problematiza é, frente ao número expressivo de 9,6 milhões de jovens denominados de "nem-nem", quais são as expectativas de futuro desses jovens? Ademais, considera-se pertinente questionar: quais têm sido as políticas públicas voltadas para a juventude? Logicamente que algumas políticas poderiam ser mencionadas, no entanto a maioria absoluta destas se relaciona somente à escolarização. Portanto, quais são as ações direcionadas aos jovens que não estão vinculados a uma instituição de ensino, ou a um programa laborativo? Quais são as expectativas para os jovens da classe trabalhadora? Qual é o projeto para os jovens negros e pobres? Encarcerar? Infelizmente, frente aos dados apresentados, parece que essa tem sido a escolha: 
aprisionar. E, da forma como a discussão da PEC nº 171 de 1993 tem sido conduzida, a "milagrosa solução" apresentada é sim encarcerar: “o quanto antes melhor!”.

\section{Considerações Finais}

Ao se tratar de jovens reclusos ou em cumprimento de medida socioeducativa de restrição de liberdade, um conjunto de discussões e trabalhos demonstra que, juntamente com a privação de liberdade, esses jovens têm comumente perdido os demais direitos que lhes deveriam ser garantidos ao estarem sob a custódia do Estado. São trabalhos de suma importância, na medida em que demonstram como, no interior das instituições punitivas, os direitos humanos têm sido desconsiderados.

No entanto, é preciso considerar que as pessoas que compõe a população prisional do país, em sua maioria, têm um histórico de exclusão social. Assim, ao serem encarceradas, continuam a não ter direitos, não os perdem, porque nunca os tiveram. Exemplo disso é que se verifica que a maioria absoluta dos jovens reclusos, seja no sistema socioeducativo ou no sistema prisional, possui escolaridade deficitária e/ou não chegaram a serem inseridos no mercado de trabalho formal.

Os dados apresentados neste trabalho indicam a tendência de hiperencarceramento e seletividade racial como características do sistema prisional brasileiro. Além disso, chama a atenção para o tratamento atualmente dispensando no país à juventude da classe trabalhadora, degenerada pelos órgãos de justiça e segurança pública. Enfatiza-se a emergência de estudos que discutam a temática e indiquem alternativas para o rompimento do círculo da violência praticado contra essa parte da população. Tendo como foco, por exemplo, as questões relativas ao acesso à educação e ao trabalho, a fim de verificar a efetivação desses direitos.

Ressalta-se ainda a necessidade da promoção da inclusão social dos jovens que vivem em áreas caracterizadas pelas altas taxas de vulnerabilidade e, inclusive, da discussão sobre a prisão como extensão dessas áreas.

\section{Referências}

ALVES, Joseane Duarte Ouro. A criminalização da questão social: uma juventude encarcerada. 2013. 186f. Dissertação (Mestrado) - Universidade Federal de Juiz de Fora. Juiz de Fora, 2013. 
BRASIL. Lei n ${ }^{\circ}$ 12.852, de 5 de agosto de 2013. Diário Oficial da União, Brasília, 06 ago. 2013. Disponível em: < http://www.planalto.gov.br/ccivil_03/_Ato2011-2014/2013/Lei/L12852.htm > Acesso em: 08 out. 2015.

- Ministério da Justiça (MJ). Levantamento Nacional de Informações Penitenciárias (Infopen) - junho de 2013. Disponível em: < http://www.justica.gov.br/seusdireitos/politica-penal/transparencia-institucional/estatisticas-prisional/anexos-sistemaprisional/total-brasil-junho-2013.pdf>. Acesso em: 22 de set. 2014.

- Ministério da Justiça (MJ). Levantamento Nacional de Informações Penitenciárias (Infopen) - junho de 2014.2015a. 148 p. Disponível em: <http://www.justica.gov.br/noticias/mj-divulgara-novo-relatorio-do-infopen-nesta-tercafeira/relatorio-depen-versao-web.pdf >. Acesso em: 17 jul. 2015.

. Presidência da República. Secretaria Geral. Mapa do Encarceramento: os jovens do Brasil. Brasília: Presidência da República, 2015b. 112 p. Disponível em: <http://www.pnud.org.br/arquivos/encarceramento_WEB.pdf> Acesso em: 10 set. 2015.

- Ministério da Previdência Social. Empresa de Tecnologia e Informações da Previdência Social (Dataprev). Disponível em: 〈www3.dataprev.gov.br/scripts10/dardoweb.cgi〉. Acesso em: 12 set. 2015.

FÓRUM BRASILEIRO DE SEGURANÇA PÚBLICA. Anuário Brasileiro de Segurança Pública. São Paulo. $2015 . \quad$ 156p. Disponível em: http://www.forumseguranca.org.br/storage/download//anuario_2015-retificado.pdf. Acesso em: 17 out. 2015 
IBGE. Instituto Brasileiro de Geografia e Estatística. Censo Demográfico: 2010. Disponível em:<http://www.ibge.gov.br/home/presidencia/noticias/noticia_visualiza.php?id_noticia=1766> Acesso em: 10 set. 2015.

IBGE. Instituto Brasileiro de Geografia e Estatística. Síntese de Indicadores Sociais: uma análise das condições de vida da população brasileira. 2013. Disponível em: <http://biblioteca.ibge.gov.br/visualizacao/livros/liv66777.pdf> Acesso em 14 set. 2015.

WACQUANT, Loic. As prisões da miséria. Rio de Janeiro: Jorge Zahar, 2001 . Punir os pobres: a nova gestão da miséria nos Estados Unidos. Rio de Janeiro: Revan, 2003. . O estigma racial na construção do Estado punitivo americano. Configurações (on-line). 5/6 - 2009. Disponível em: <http://configuracoes.revues.org./88>. Acesso em: 31 out. 2015 